\title{
Evolutionary Changes in Genomic DNA Constituents and the Duration of Cell Cycle in Lathyrus species
}

\author{
S. D. Ahmad and R. K. J. Narayan \\ Institute of Biological Sciences, University of Wales Aberystwyth, Aberystwyth, UK
}

Accepted November 24, 1994

Comparisons among species of diverse plant genera have shown that the duration of mitotic cell cycle in comparable tissues is generally correlated with the amount of $2 \mathrm{C}$ nuclear DNA (Van't Hof and Sparrow 1963, Van't Hof 1965, Evans and Ress 1971). Ayonoadu and Ress (1968) have shown that by the addition of B chromosomes in the chromosome complements the duration of mitotic cycle was increased to a disproportionate extent. Larger amounts of nuclear DNA seems to prolong all phases of the cell cycle (Wallace and Maden 1976, Horner and Mcgregor 1983). In eukaryotes genomic DNA is made up of varying amounts of heterochromatin and euchromatin constituents. Very little is known at present about the effects of changes in the amounts of heterochromatin and euchromatin DNA upon the duration of mitotic cycle. Heterochromatin and euchromatin DNA have different replicative properties which may have important effects on the duration of cell cycle and its component phases. Replication of heterochromatin occurs late in $\mathbf{S}$ phase although its replication rate may be higher than that of euchromatin (Collins 1978, Schmid 1980). Changes in the amounts of the heterochromatin component even in the absence of changes in genome size would have significant effect on the duration of cell cycle (Mcgregor and Sessions 1986).

The genus Lathyrus comprises diploid species all with the same chromosome number $2 \mathrm{n}=$ 14. A five-fold variation in $2 \mathrm{C}$ nuclear DNA amounts between species has occurred during evolution. This large scale variation was associated with changes in the amounts of heterochromatin and euchromatin DNA constituents (Narayan 1986, Narayan and McIntyre 1989).

The objectives of the present investigations were to find out a) Whether large scale variation in $2 \mathrm{C}$ nuclear DNA amounts between closely related Lathyrus species has a significant effect upon the duration of total mitotic cycle. b) Whether the variation in the amounts of heterochromatin and euchromatin DNA has any effect upon the duration of complete mitotic cycle and its component phases.

Material and methods

\section{Plant material}

Four Lathyrus species, $L$. angulatus, $L$. sativus, L. hirsutus and $L$. tingitanus used in this investigation were annuals with similar plant habits and overlapping geographical distributions. The seeds were from a collection maintained at Aberystwyth. The surface sterilised seeds were germinated on moist filter papers kept under sterile conditions in a growth chamber set at $25^{\circ} \mathrm{C}$.

Measurement of the duration of mitotic cycle and its component phases

6- ${ }^{3} \mathrm{H}$ thymidine (TRA. 61, Amersham International, UK) was made up to a final concentration of $2 \mu \mathrm{Ci} / \mathrm{ml}$ with sterile distilled water. The final chemical concentration was 0.1 $\mu \mathrm{g} / \mathrm{ml}$. Two day old seedling were placed in a beaker of pre-warmed ${ }^{3} \mathrm{H}$ thymidine solution

Address for correspondence: Dr. R. K. J. Narayan, Sir George Stapledon Building, Institute of Biological Sciences, University of Wales, Aberystwyth SY23 3DD Wales, UK. 
exactly for $30 \mathrm{~min}$ at $25^{\circ} \mathrm{C}$. After treatments the seedlings were thoroughly washed in distilled water and placed on moist filter papers in an incubator set at $25^{\circ} \mathrm{C}$. Five root tips were fixed in 1:3 acetic-alcohol at two hour intervals for $30 \mathrm{hr}$. The first sample was fixed at zero hour after labelling. The root meristems stained in Feulgen were squashed on acid-cleaned slides. The slides were dehydrated by passing through 50\%,70\% and absolute ethanol. After air drying the slides were dipped in Kodak $\mathrm{K}_{2}$ emulsion (diluted 1:1 with distilled water) and left for auto radiography for 3 weeks in light-tight boxes. The slides were then developed in Kodak D-19 developer. The slides were made permanent by mounting in euparal under a cover slip.

Three slides (root tips) at each time interval formed the replications. 100 prophase cells were scored at random in each slide to estimate the proportion of labelled prophase cells. The average values estimated from the 3 replications were used to plot the mitotic cycle curves. The curve fitting was done using Harvard graphic computer programme. The duration of the total mitotic cycle and of the component phases [synthesis (S), division or mitosis (M), postsynthesis $\left(G_{2}\right)$ and pre-synthesis $\left(G_{1}\right)$ ] were calculated by the method given by Evans and Rees (1971).

\section{Measurement of $2 C$ nuclear DNA amounts in Lathyrus species}

Primary root tips from seedlings grown under axenic conditions were fixed in 4\% neutral formaldehyde $(v / v)$ for two hours at room temperature. Neutral formaldehyde was prepared as a $1: 10$ dilution of $40 \%$ formaldehyde in phosphate buffer (equimolar mixture of $0.066 \mathrm{M}$ $\mathrm{Na}_{2} \mathrm{HPO}_{4}$ and $0.066 \mathrm{M} \mathrm{KH} \mathrm{PO}_{4}, \mathrm{pH}, 7.0$ ). The root tips were thoroughly washed in several changes of distilled water for $24 \mathrm{hr}$. They were fixed again in $1: 3$ acetic-alcohol and stored at $0^{\circ} \mathrm{C}$ for at least $48 \mathrm{hr}$.

The method for the quantitative staining of DNA was similar to that suggested by Teoh and Rees (1976). The DNA measurements were made on a Vickers M85 micro-densitometer. Species were measured in batches of eight which included Allium cepa as control. Small variation between batches was standardised using the control species Allium cepa $(2 \mathrm{C}=33.5$ pg) which was also used to convert the DNA estimates into absolute amounts. All DNA measurement experiments consisted of at least 2 replications. At least two plants were measured in each replication and twenty $2 \mathrm{C}$ nuclei were measured in each root tip. Analysis of variance showed no significant differences between $2 \mathrm{C}$ nuclei within root tips and between plants within replications.

\section{Measurement of heterochromatin and euchromatin DNA in the chromosome complement}

The method for the measurement of the DNA constituents in the C-banded chromosome complements is previously described (Narayan and McIntyre 1989, Narayan and Durrant 1983). The method, in brif, was as follows. The mitotic chromosome preparations were made using root tips collected from germinating seeds. The chromosomes were arrested at metaphase by treating the root tips with $0.1 \%$ colchicine for $3 \mathrm{hr}$. The root tips were fixed in $1: 3$ acetic alcohol for at least $48 \mathrm{hr}$. Metaphase chromosome preparations were stained with Giemsa according to the method suggested by Vosa (1974), Figs. 1, 2 and 3 . The C-banded chromosome preparations were made permanent by mounting them in euparal. At least 3 full metaphase plates were used to measure the relative amounts of heterochromatin and euchromatin DNA in chromosomes. Chromatid lengths and widths were measured accurately using a micrometer eye piece. The volumes of heterochromatic $\mathrm{C}$-bands and euchromatic regions were measured separately by this method for each chromosome. The relative densities of heterochromatin and euchromatin were measured by spot microdensitometry using a masking device available with M86 Vickers microdensitometer. The herochromatin was on average 1.6 times denser than euchromatin. Using the volumes of heterochromatin and euchromatin and 


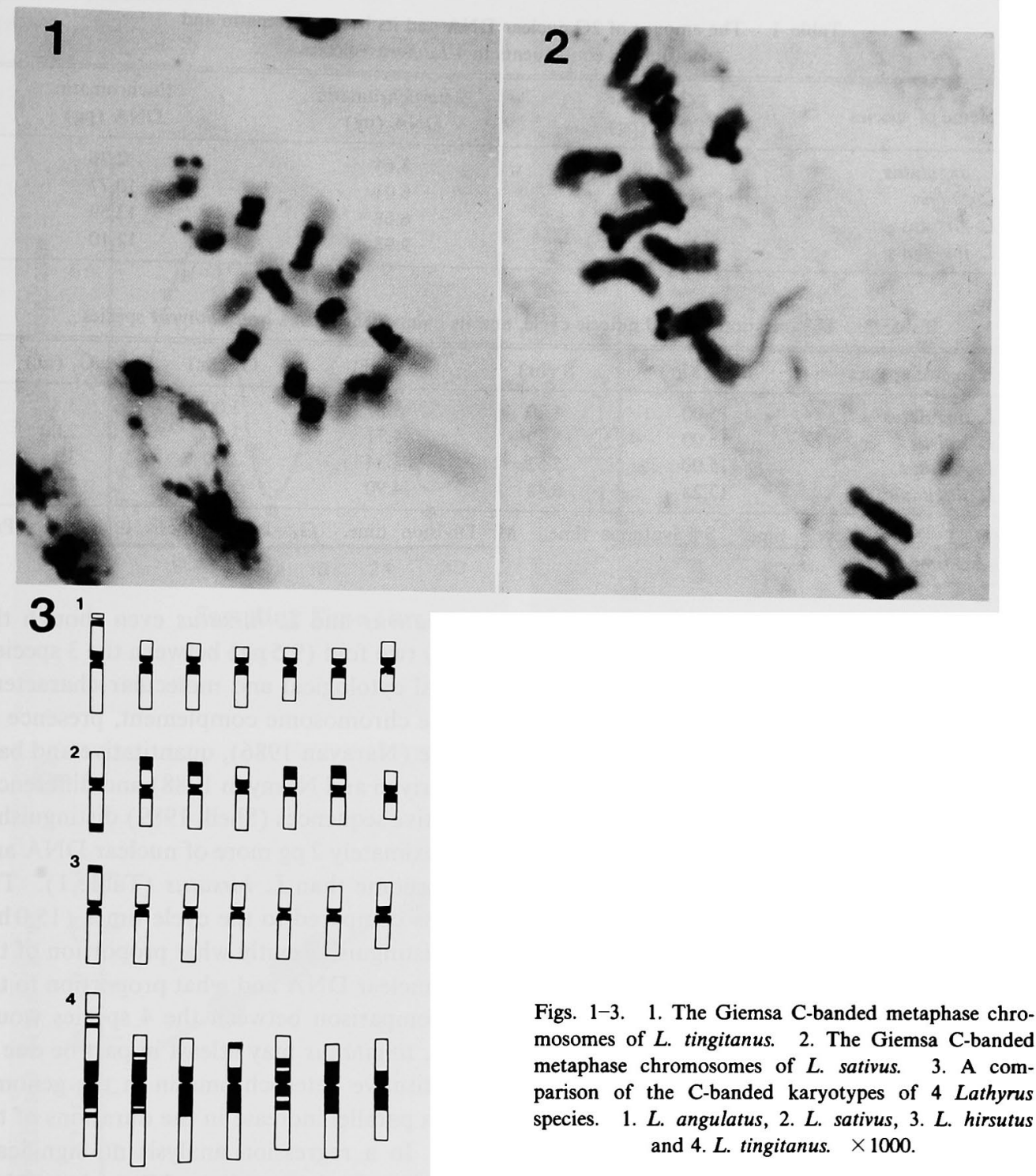

their relative densities the amounts of DNA contained in each constituent was estimated.

\section{Results and conclusions}

The 2C nuclear DNA amounts and the amounts of heterochromatin and euchromatin DNA in picograms in the chromosome complements of 4 Lathyrus species are given in Table 1. The variation in $2 \mathrm{C}$ nuclear DNA amount is two fold between the 4 species; it ranges from $10.76 \mathrm{pg}$ in L. angulatus to $22.08 \mathrm{pg}$ in L. tingitanus. The variation in the amount of heterochromatin and euchromatin constituents is also large among the 4 species. L. tingitanus has a disproportionately large amount of heterochromatin in the chromosome complement (Table 1 and Figs. 1,2). The mitotic cycle time curve for $L$. angulatus which is typical for the 4 species is shown in Fig 4 . The duration of the total cell cycle time as well as the duration of its individual component phases estimated from the mitotic cycle curves are given in Table 2. 
Table 1. The amount of $2 \mathrm{C}$ nuclear DNA and its heterochromatin and euchromatin constituents in 4 Lathyrus species

\begin{tabular}{lccc}
\hline \hline Name of species & $\begin{array}{c}\text { 2C nuclear } \\
\text { DNA }(\mathrm{pg})\end{array}$ & $\begin{array}{c}\text { Heterochromatin } \\
\text { DNA }(\mathrm{pg})\end{array}$ & $\begin{array}{c}\text { Euchromatin } \\
\text { DNA }(\mathrm{pg})\end{array}$ \\
\hline L. angulatus & 10.90 & 3.64 & 7.26 \\
L. sativus & 16.78 & 6.01 & 10.77 \\
L. hirsutus & 20.27 & 6.68 & 13.59 \\
L. tingitanus & 22.08 & 9.98 & 12.10 \\
\hline
\end{tabular}

Table 2. The duration of total mitotic cycle, and its component phases in 4 Lathyrus species

\begin{tabular}{lccccc}
\hline \hline Name of species & MCT (hr) & $\mathrm{S}(\mathrm{hr})$ & $\mathrm{M}(\mathrm{hr})$ & $\mathrm{G}_{2}(\mathrm{hr})$ & $\mathbf{G}_{1}(\mathrm{hr})$ \\
\hline L. angulatus & 15.00 & 4.30 & 3.87 & 3.00 & 3.83 \\
L. sativus & 15.00 & 5.29 & 4.71 & 3.00 & 2.00 \\
L. hirsutus & 15.00 & 5.52 & 4.34 & 2.00 & 3.14 \\
L. tingitanus & 17.25 & 6.48 & 4.90 & 3.50 & 2.37 \\
\hline
\end{tabular}

MCT $=$ Mitotic cycle time. $S=$ Synthesis time. $\quad M=$ Division time. $G_{2}=$ Post-synthesis time. $G_{1}=$ Presynthesis time.

The total cycle time is similar for $L$. angulatus, $L$. sativus and $L$. hirsutus even though the variation in $2 \mathrm{C}$ nuclear DNA amounts is approximately two fold $(9.5 \mathrm{pg})$ between the 3 species. The genome of $L$. tingitanus is exceptional for several cytological and molecular characters. The unusually large amount of heterochromatin in the chromosome complement, presence of a variety of satellite DNA sequences within the genome (Narayan 1986), quantitative and base compositional differences in the repetitive families (Kuriyan and Narayan 1988) and differences in the interspersion pattern of repetitive and non repetitive sequences (Sheik 1989) distinguishes L. tingitanus from other Lathyrus species. It has approximately $2 \mathrm{pg}$ more of nuclear DNA and about $3.3 \mathrm{pg}$ more of heterochromatin DNA in the genome than L. hirsutus (Table 1). The total cycle time in L. tingitanus is greater $(17.25 \mathrm{hr})$ as compared to the cycle times $(15.0 \mathrm{hr})$ in the other 3 species compared. It is not possible to distinguish exactly what proportion of the increase in total cycle time was due to the increase in nuclear DNA and what proportion to the effect of heterochromatin. Nevertheless, a careful comparison between the 4 species would suggest that the increase in the mitotic cycle time in $L$. tingitanus may atleast in part be due to the disproportionate increase in the amount of constitutive heterochromatin in the genome. The increase in the total cycle time has resulted from a parallel increase in the durations of the component phases synthesis, division $(M)$ and $G_{2}$. In a regression analysis no significant correlation $(p>0.05)$ was observed between the total cycle time and the $2 \mathrm{C}$ nuclear DNA amounts for the 4 species.

The $\mathbf{B}$ chromosomes in rye (Secale cereale) are predominantly made up of heterochromatin which replicates late in the interphase. Ayonoadu and Rees (1968) has shown that the addition of $\mathbf{B}$ chromosomes in the genome increases the duration of complete mitotic cycle. The rate of increase in the duration was greater than that was attributable to the extra DNA in the $B$ chromosomes. They have concluded that the influence of heterochromatic $B$ chromosomes upon the duration of the mitotic cycle and its component phases was not entirely a direct consequence of the increasing nuclear mass. The increase in the duration of complete cycle was paralleled by increases in the duration of phases, $\mathbf{G}_{2}, S$ and division.

No significant correlation was obtained when total mitotic cycle time was regressed separately against the amounts of heterochromatin DNA and euchromatin DNA $(p>0.05)$ in the 4 species. In Lathyrus evolutionary increase in total nuclear DNA is accompanied by an increase in the amount of both heterochromatin and euchromatin (Narayan 1986). Such 
4

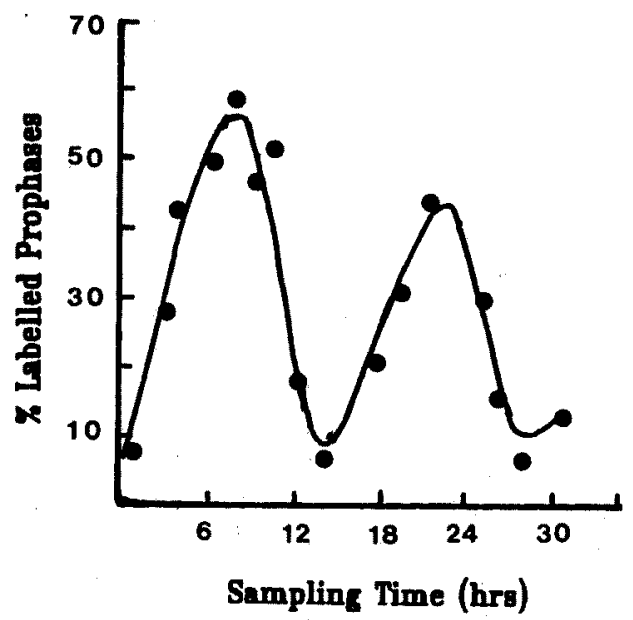

6

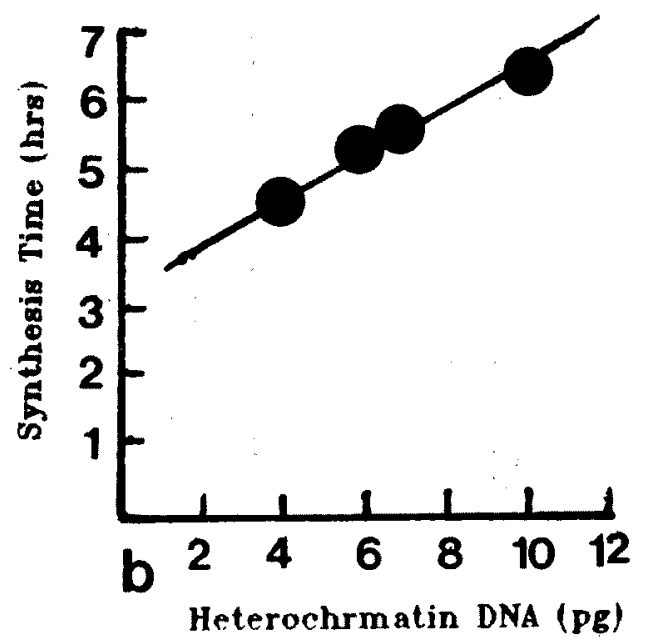

5

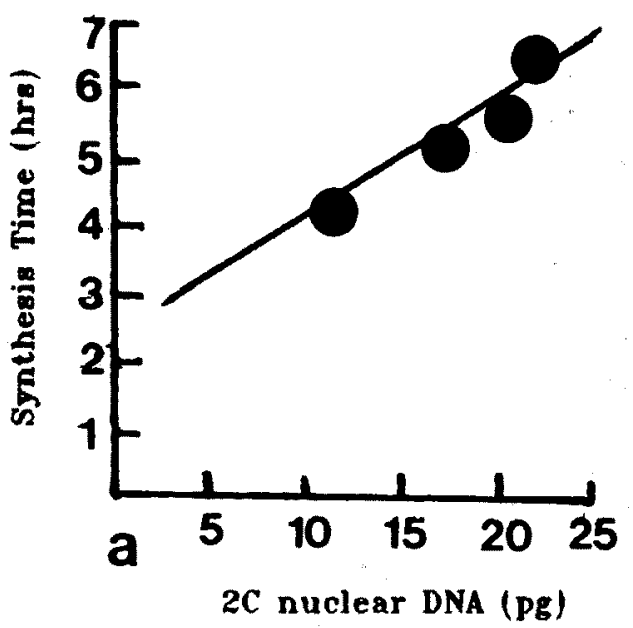

7

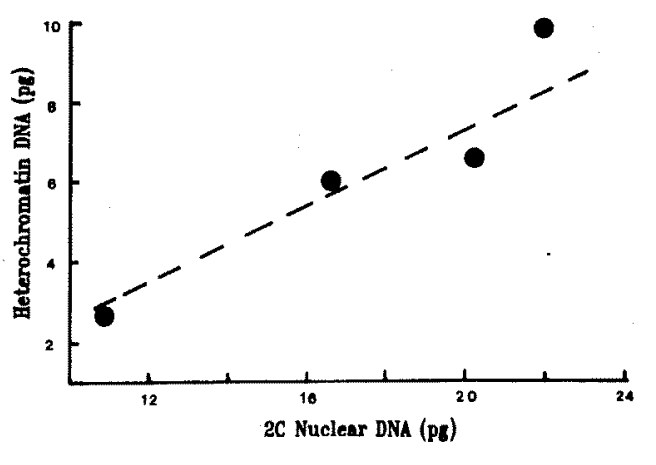

Figs. 4-7. 4. The mitotic cycle curve for $L$. angulatus which is typical for the 4 species investigated. 5. The duration of synthesis time for the 4 Lathyrus species is regressed against their respective $2 \mathrm{C}$ nuclear DNA amounts. The regression is significant at the 5\% level. 6. Synthesis time is regressed against the heterochromatin DNA in 4 Lathyrus species. The regression is significant at the $1 \%$ level. 7 . The amounts of heterochromatin DNA in 4 Lathyrus species are plotted against their $2 \mathrm{C}$ nuclear DNA amounts. The regression is not significant at the $5 \%$ level. The best fitting line is shown as dotted line. 
gradual evolutionary changes in the amount of heterochromatin in the genome appears to have no significant effect upon the duration of mitotic cycle as seen in $L$. angulatus, $L$. sativus and $L$. hirsutus. A disproportionate increase in the amount of heterochromatin in L. tingitanus appears to have modified the duration of the complete cycle and its component phases. In Fig. 7 the amount of heterochromatin DNA is plotted against total DNA in the 4 Lathyrus species. The regression is not significant at the $5 \%$ level. L. tingitanus shows a greater departure from the best fitting regression line.

In Fig. 5 the duration of synthesis is plotted against the $2 \mathrm{C}$ nuclear DNA amounts. The regression is linear and significant $(p<0.05)$. In other words the synthesis time increases linearly with the increase in total DNA amounts. In Fig. 6 the synthesis time is plotted against the heterochromatin DNA in the genomes of the 4 species. As with the total DNA the regression is linear and highly significant $(\mathrm{p}<0.01)$. In $L$. angulatus, L. sativus and $L$. hirsutus although the duration of synthesis time is increased with increase in the amounts of heterochromatin DNA the compete cycle time has remained constant. This is achieved by a reduction in the duration of other phases of the cell cycle. The heterochromatin DNA replicates asynthronously with respect to the rest of the genome (McGregor and Sessions 1986). Collins (1978) has reported that the replication of heterochromatin occurs late in the S phase although its rate of replication may be greater than that of euchromatin. The different replicative properties of heterochromatin and euchromatin may be responsible for the variation in the duration of synthesis time in $L$. angulatus, $L$. sativus and $L$. hirsutus and in the duration of all phases in $L$. tingitanus which is exceptional.

Similar comparisons were made using euchromatin DNA. There was no significant correlation between the amounts of euchromatin DNA and the duration of synthesis.

Amounts of $2 \mathrm{C}$ nuclear DNA and the amounts of its constituents, heterochromatin and euchromatin DNA were taken in turn and regressed separately against the duration of division $(M)$, pre-synthesis $\left(G_{1}\right)$ and post-synthesis $\left(G_{2}\right)$ phases. In the analyses of variance no significant relationship was observed.

The following conclusions are drawn from the investigation.

1. Among related species, within a genus, the duration of the complete mitotic cycle is not correlated with genome size. There is no significant correlation with the amounts of DNA constituents (heterochromatin and euchromatin) which are gradually accrued in evolution. A disproportionate increase in heterochromatin, as with the addition of heterochromatic $B$ chromosomes in rye or as in the speciation of $L$. tingitanus, seems to prolong the complete cyle and the component phases.

2. The duration of synthesis is positively correlated with the amount of total DNA and the amount of heterochromatin DNA in the genome.

3. The durations of division, $G_{1}$ and $G_{2}$ are not correlated with the variation in the amount of total DNA, heterochromatin DNA and euchromatin DNA.

\section{Summary}

The duration of the complete mitotic cycle and its component phases were compared with the amounts of 2C nuclear DNA, heterochromatin DNA and euchromatin DNA in four Lathyrus species. The total cycle time as a whole was not correlated with the variation in $2 \mathrm{C}$ nuclear DNA amount which was two fold between the 4 related species. However, the duration of synthesis phase was positively correlated with the amounts of total DNA and heterochromatin DNA. The results have further shown that a disproportionate increase in the amount of heterochromatin in the genome can increase the total duration of the mitotic cycle as well as the duration of its component phases. 
Key words: Nuclear DNA, Heterochromatin DNA, Euchromatin DNA, Cell cycle time, Genus Lathyrus.

\section{References}

Ayonoadu, U. W. U and Rees H. 1968. The regulation of mitosis by B chromosomes in rye. Exp. Cell Res. 52: 284290.

Collins, J. M. 1978. Rates of DNA synthesis during the S phase Hela cells. J. Biol. Chem. 253: 8570-8577.

Evans, G. M. and Rees, H. 1971. Mitotic cycle in dicotyledons and monocotyledons. Nature 233: 450-451.

Horner, H. A. and McGregor, H. C. 1983. C value and cell volume: their significance in the evolution and development of amphibians. J. Cell Sci. 63: 135-146.

Kuriyan, P. N. and Narayan, R. K. J. 1988. The distribution and divergence in evolution of families of repetitive DNA sequences in Lathyrus species. J. Mol. Evol. 27: 303-310.

MacGregor, H. C., Vlad, M. and Barnett, L. 1977. An investigation of some problems concerning nucleolus organisers in salamanders. Chromosoma 59: 283-299.

- and Sessions, S. K. 1986. The biological significance of variation in satellite DNA and heterochromatin in newts of the genus Triturus: an evoltionary perspective. Phil. trans. R. Soc. Lond. B. 321: 243-259.

Narayan, R. K. J. and Durrant, A. 1983. DNA distribution in chromosomes of Lathyrus species. Genetica 61: 47-53.

- 1986. DNA changes in chromosome differentiation and evolution in Lathyrus. In Lathyrus and Lathyrism (Kaul, A. K. and Coombes, D. eds.) p. 67. Third world medical research foundation, New York.

- and McIntyre, F. K. 1989. Chromosomal DNA variation, genomic constraints and recombination in Lathyrus. Genetica 79: 45-52.

Schmid, M. 1980. Cytological aspects of DNA synthesis in the late replicating regions of the human gemone. Genet. Polonica 21: 211-220.

Sheik, A. H. 1989. Interspersion of non repetitive and repetitive DNA sequences in Lathyrus species. MSc thesis submitted to the University College of Wales, Aberystwyth.

Teoh, S. B. and Rees, H. 1976. Nuclear DNA amounts in populations of Picea and Pinus species. Heredity 36(1): 123137.

Van't Hof, J. and Sparrow, A. H. 1963. A relationship between DNA content, nuclear volume and minimum mitotic cycle time. Proc. Natl. Acad. Sci. USA 49: 897-902.

- 1965. Relationship between mitotic cycle duration, $S$ period duration and average rate of DNA synthesis in the root meristem cells of several plants. Exp. Cell Res. 39: 48-58.

Vosa, C. G. 1974. The basic karyotype of rye (Secale cereale) analysed with Giemsa and flourescence methods. Heredity 33(3): 403-408.

Wallace, H. and Maden, M. 1976. The cell cycle during amphibian limb regeneration. J. Cell Sci. 20: 539-547. 